\title{
KAJIAN ATAS PEMIKIRAN MOHAMMAD ILYAS TENTANG KALENDER ISLAM INTERNASIONAL
}

\author{
Juwartin \\ Fakultas Syariah UIN Maulana Malik Ibrahim Malang \\ Email:juwartin@yahoo.co.id
}

\begin{abstract}
Abstrak
The problems of determining the beginning of the month Qamariyah among Muslims until now has not been also found an appropriate solution. And so we need a method that can minimize and even reduce the differences that had existed among Muslims, especially in determining the times of Muslim worship. One of the phenomenal character of Prof. Dr. Mohammad Ilyas from Malaysia, who have an idea of the International Islamic Calendar. Seeing the condition of Muslims who are always different in the initial determination Qamariyah months, as scientists, Ilyas eventually led to the idea. In this paper presented the idea Ilyas of the International Islamic Calendar and the problems it faces.

Problematika penentuan awal bulan Qamariyah di kalangan umat Islam sampai saat ini belum juga ditemukan solusi yang sesuai. Sehingga dibutuhkan metode yang mampu meminimalisir bahkan meredam perbedaan-perbedaan yang selama ini ada di kalangan umat Islam, khususnya dalam penentuan waktuwaktu ibadah umat Islam. Salah satu tokoh fenomenal yaitu Prof. Dr. Moh Ilyas dari Malaysia, yang mempunyai gagasan tentang adanya Kalender Islam Internasional. Melihat kondisi umat Islam yang selalu berbeda dalam penentuan awal bulan Qamariyah, sebagai ilmuan, Ilyas akhirnya memunculkan ide tersebut. Dalam tulisan ini dipaparkan mengenai gagasan Ilyas tentang Kalender Islam Internasional beserta problematika yang dihadapinya.
\end{abstract}

Kata Kunci: Mohammad Ilyas, Kalender Islam Internasional

Bagi umat Islam di dunia, penentuan awal bulan Qamariyah merupakan suatu hal yang sangat urgen dan sangat diperlukan ketepatannya, sebab pelaksanaan ibadah dalam ajaran Islam banyak dikaitkan dengan sistem penanggalan ini. Seringnya terjadi perbedaan dalam menetapkan awal bulan menyebabkan sebagian masyarakat bingung dengan perbedaan tersebut. Sebenarnya yang menjadi persoalan dalam hal ini adalah apa tanda atau kriteria yang menunjukkan bahwa bulan itu adalah bulan baru sehingga orang mengetahuinya, dan bagaimana cara mengetahui tanda atau kriteria itu. Tanda atau kriteria inilah yang akan menjelaskan kapan bulan itu tiba atau kalau diperluas, kapan bulan Qamariyah itu berganti dari bulan lama ke bulan baru.

Dalam penentuan awal bulan Qamariyah, hilal sangat berperan, karena hilal dapat memberi tanda masuknya waktu ibadah umat Islam. Penetapan posisi hilal dalam penentuan awal bulan Qamariyah sangat penting, terutama dalam hal ibadah yang pelaksanaannya berdasarkan penanggalan Hijriyah.

Penentuan hilal tersebut sering terjadi polemik dan perdebatan yang tidak ada habisnya. Penetapan awal bulan Qamariyah merupakan salah satu lahan ilmu hisab rukyat yang kerap diperdebatkan. Menurut Ibrahim Husein sebagaimana dipetik oleh Izzuddin, persoalan ini dikatakan sebagai persoalan klasik yang senantiasa aktual. Klasik karena persoalan ini semenjak masa-masa awal Islam sudah mendapatkan perhatian dan pemikiran yang cukup mendalam dan serius dari pakar hukum Islam. Dikatakan aktual, karena hampir setiap tahun terutama menjelang Ramadhan, Syawal, dan Dzulhijjah, persoalan ini selalu mengundang polemik berkenaan dengan pengaplikasian pendapat-pendapat tersebut.

Permasalahan umat Islam yang satu ini belum terselesaikan dengan tuntas hingga detik ini, bahkan perbedaan semakin menjamur. Dari sinilah muncul berbagai pendapat dan upaya-upaya untuk persatuan umat Islam itu sendiri khususnya dalam penyatuan bulan Qamariyah atau kalender Hijriyah. Salah satu tokoh yang gencar menggagas penyatuan kalender umat Islam yaitu Moh. Ilyas dari Malaysia.

Dalam pembahasan ini, penulis akan membahas gagasan penetapan kalender Hijriyah dengan melakukan studi terhadap pemikiran Moh. Ilyas tentang 
kalender Islam internasional sebagai solusi penyatuan dan kompromi terhadap perbedaan hisab dan rukyat serta penyatuan kriteria bersama, yang dijadikan sebagai pedoman.

\section{Kalender Islam}

Kalender adalah sebuah sistem pengorganisasian waktu untuk penghitungan waktu selama periode tertentu. Secara konvensi, hari adalah unit kalender terkecil, sementara untuk pengukuran bagian dari sebuah hari digunakan sistem penghitungan waktu (jam, menit, dan detik). Beberapa sistem kalender mengacu pada suatu siklus astronomi yang megikuti aturan yang tetap, tetapi beberapa sistem kalender ada yang mengacu pada sebuah aturan yang abstrak dan hanya mengikuti sebuah siklus yang berulang tanpa memiliki arti secara astronomis. Ada kalender yang dikode berdasarkan hukum tertulis, tapi ada juga yang disampaikan melalui pesan-pesan moral.

Menurut sebuah studi tahun 1987, disebutkan bahwa ada sekitar 40 sistem kalender yang saat ini digunakan di dunia dan dikenal dalam pergaulan internasional, namun secara umum dikategorikan ke dalam tiga madzhab besar dalam penghitungan kalender. Yang pertama, adalah sistem kalender matahari (syamsiyyah) atau solar calendar, yaitu sistem kalender yang penghitungannya berdasarkan pada perjalanan bumi saat melakukan revolusi mengorbit pada matahari. Kalender Gregorian yang digunakan untuk keperluan sipil di seluruh dunia adalah sistem kalender matahari yang dirancang agar tetap sinkron dengan tahun tropis (musim). Untuk menjaga sinkronisasi ini, jumlah harinya disisipi (dalam bentuk tahun kabisat atau leap year) sebagai tambahan pada jumlah hari rata-rata kalender tersebut. Yang kedua, adalah kalender bulan $^{1}$ (qamariyah) atau lunar calendar yang berdasarkan pada perjalanan bulan selama mengorbit (ber-revolusi terhadap) bumi.

Kalender Islam adalah murni lunar kalender yang mengikuti siklus fase bulan tanpa ada keterkaitan dengan tahun tropis. Itulah sebabnya, jumlah hari dalam kalender Islam selalu secara sistematis bergeser (lebih pendek sekitar 11,53 hari pertahun) dari pada Kalender Gregorian. Yang ketiga, adalah lunisolar calendar yang merupakan gabungan atas kedua sistem di atas. Kalender lunisolar memiliki urutan bulan yang mengacu pada siklus fase bulan,

\footnotetext{
1 Ada ambiguitas dalam istilah bulan dalam bahasa Indonesia, karena kata bulan digunakan untuk bulan (Inggris: month), dan Bulan (Inggris: moon) yang merupakan satelitnya Bumi. Oleh karenanya, untuk selanjutnya sistem kalender bulan disebut saja dengan sistem kalender qamariyah atau lunar calendar.
}

namun pada setiap berbagai tahun tertentu ada sebuah sisipan (intercalacy month) diberikan agar kalender ini tetap sinkron dengan kalender musim (solar calendar). Kalender Yahudi, China, dan Kalender Arab pra-Islam adalah contoh kalender jenis ini. ${ }^{2}$

Dalam literatur klasik maupun kontemporer, istilah kalender biasa disebut dengan târîk $h^{3}$, taqwîm ${ }^{4}$, almanak $^{5}$, dan penanggalan ${ }^{6}$. Istilah-istilah tersebut pada prinsipnya memiliki makna yang sama. ${ }^{7}$ Salah satu sumber referensi yang menarik adalah karya P.J. Bearman, The Encyclopaedia of Islam (2000). Dalam buku ini pengarang melakukan sebuah studi etimologis kecil tentang berbagai istilah yang berkaitan dengan makna kalender Hijriyah. Menurutnya, kalender Hijriyah adalah kalender yang terdiri dari dua belas bulan Qamariyah, setiap bulan berlangsung sejak penampakan pertama bulan sabit hingga penampakan berikutnya (29 hari atau 30 hari). ${ }^{8}$ Selain itu, dalam Leksikon Islam menyebutkan bahwa kalender Hijriyah atau Tarikh Hijriyah adalah penanggalan Islam yang dimulai dengan peristiwa hijrah Rasulullah SAW.

Moedji Raharto dalam artikelnya yang berjudul "Di Balik Persoalan Awal Bulan Islam” menjelaskan bahwa kalender Hijriyah atau penanggalan Islam adalah sebuah sitem kalender yang tidak memerlukan pemikiran koreksi, karena betul-betul mengandalkan fenomena fase bulan. Sejalan dengan itu, Thomas Djamaluddin berpendapat bahwa kalender Qamariyah merupakan kalender yang paling sederhana, yang mudah dibaca di alam. Awal bulan ditandai oleh penampakan hilâl (visibilitas hilal) sesudah matahari terbenam (Maghrib). Sedangkan Basit Wahid yang juga menaruh perhatian terhadap kalender Hijriyah

2 Tono Saksono, Mengkompromikan Rukyat \& Hisab (Jakarta: P.T. Amythas Publicita, 2007), h. 47.

3 F. Steingass, Arabic-English Dictionary, (New Delhi: Cosmo Publications, 1978), h.. 158., Hans Wehr, Dictionary of Modern Written Arabic, (Germany: Otto Harrassonitz, 1994), h. 15., Noor Ahmad, Risâlah Syams al-Hilâl (Kudus: Madrasah Tasywiqât-Tullâb Salâfiyah, t. th.), h. 7.

4 Munir Ba'albaki, al-Mawrid A Modern English-Arabic Dictionary, (Beirut: Dâr al-'Ilm li al-Malâyin, 1974), h. 144., Ahmad al-Khatib, A New Dictionary of Scientific \& Technical Terms, (Libanon: Maktabah Libanon, t. th.), h. 77., Mohamad Khair bin Mohamad Taib, Takwim Istilah (HijhrahMasehi) 1401-1500 H./1980-2077 M. (Kuala Lumpur: Jabatan Perdana Menteri [Bahagian Agama] Pusat Islam, t. th).

5 Ahmad Warson Munawwir, Kamus al-Munawwir Arab-Indonesia Terlengkap, (Surabaya: Pustaka Progresif, t. th.), h. 1263., Kata almanak juga sering dipakai di kalangan Muhammadiyah dan NU, seperti Almanak Muhammadiyah dan Almanak PB NU.

6 Panji Masyarakat, No. 582, 7-16 Dzulhijjah 1408/21-30 Juli 1988, h.7476., Panji Masyarakat, No. 718, Tahun XXXIV, 28 Syawal - 7 Dzulqa'dah 1412 H./1-10 Mei 1992 M., h. 64-67.

7 Departemen Pendidikan dan Kebudayaan, Kamus Besar Bahasa Indonesia, (Jakarta: Balai Pustaka, 1989), h. 380 dan 904.

8 Departemen Pendidikan dan Kebudayaan, Kamus Besar Bahasa Indonesia., John L. Esposito, The Oxford Encyclopaedia of Modern Islamic World, (New York: Oxford University Press, 1995), Vol. 2, h.301. 
menyatakan bahwa kalender tersebut adalah yang didasarkan pada sistem Qamariyah semata. Satu tahun ditetapkan berjumlah 12 bulan, sedang penghitungan bulan dilakukan berdasarkan fase-fase bulan atau manâzilnya. Muhammad Bâshil at-Thâiy, dalam bukunya yang berjudul "'Ilm al-Falak wa alTaqâwîm", menyatakan bahwa kalender Hijriyah adalah kalender Qamariyah yang mulai digunakan pada masa Khalifah 'Umar bin Khattab dengan mendasarkan pada hijrah Nabi SAW dari Makkah ke Madinah. ${ }^{9}$

Dalam pembahasan ini, penulis akan fokus pada kalender Islam. Kalender Islam (kalender Hijriyah) adalah murni kalender bulan (lunar calendar atau kalender Qamariyah) yang memiliki 12 bulan yang mengikuti pergerakan bulan. karena bulan sinodik ${ }^{10}$ (synodic month) hanya memiliki 12 x 29,53 hari, maka satu tahun kalender Qamariyah hanya memiliki 354,36707 hari. Hal ini berarti bahwa kalender Islam secara konsisten lebih pendek sekitar 11,256 hari dari kalender Syamsiyah (tahun tropis), dan karena hal itu juga kalender Islam selalu bergeser (maju) terhadap kalender Gregorian ${ }^{11}$ yang banyak dipakai oleh dunia internasional.

Sistem kalender apapun, apakah itu kalender matahari, kalender bulan, kalender lusionar, semuanya sepakat dalam mendefinisikan satu hari merupakan perjalanan bumi berotasi pada sumbunya yang efek-

9 Khafid, Kalender Islam Internasional: Analisis terhadap Perbedaan Sistem, (Disertasi: 2009).

10 Periode sinodis bulan merupakan selang waktu yang diperlukan bulan menempuh satu fase bulan tertentu dua kali secara berurutan. Periode sinodis bulan mensyaratkan konfigurasi yang sama antara bulan, bumi dan matahari, jika waktu ijtimak atau konjungsi sebagai acuan maka secara operasional setiap kedudukan bulan dan matahari mempunyai bujur ekliptika sama merupakan saat yang penting. Durasi yang dibutuhkan oleh bulan berada dalam suatu fase bulan baru ke fase bulan baru berikutnya (phase of the moon/aujuh al-qamar) adalah 29,530588 hari atau $29^{\mathrm{h}} 12^{\mathrm{j}} 44^{\mathrm{m}} 2,8^{\mathrm{d}}$. Lama waktu antara dua konjungsi (ijtimak) ini dikenal dengan nama periode sinodis (al-syahr al-qamar), dan periode sinodis inilah yang menjadi kerangka dasar Kalender Hijriyah. Oleh karena itu, umur bulan hijriyah bervariasi antara 29 dan 30 hari. Baca Montenbruck, O., dan Pfleger, T., Astronomy on The Personal Computer, (Berlin: Spinger-Verlag, 1994) h.40.

11 Gregorian adalah kalender yang sekarang paling banyak dipakai di Dunia Barat. Ini merupakan modifikasi Kalender Julian. Yang pertama kali mengusulkannya ialah Dr. Aloysius Lilius dari Napoli-Italia, dan disetujui oleh Paus Gregorius XIII pada tanggal 24 Februari 1582. Penanggalan tahun kalender ini, berdasarkan tahun Masehi. Kalender ini diciptakan karena Kalender Julian dinilai kurang akurat, sebab permulaan musim semi (21 Maret) semakin maju sehingga perayaan Paskah yang sudah disepakati sejak Konsili Nicea I pada tahun 325 tidak tepat lagi. Lalu pada tahun 1582, Kamis-4 Oktober diikuti Jumat-15 Oktober. Kalender Gregorius membagi menjadi dua kelas; tahun bias ayang memilki 365 hari dan tahun kabisat dengan 366 hari dengan hari sisipan (intercalasy day) terjadi pada tanggal 29 Februari yang ditentukan berdasarkan; setiap tahun genap habis dibagi empat adalah tahun kabisat, kecuali tahun genap dibagi 100, tahun krusial ini ditetapkan sebagai tahun kabisat hanya bila kuga dapat dibagi dengan 400. Baca Muhyidin Khazin, Ilmu Falak dalam Teori dan Praktik, (Yogyakarta: Buana Pustaka, 2008), hal. 104. Baca Moh. Murtadho, Ilmu Falak Praktis, (Malang: UIN Malang Press, 2008), h.95-96. nya menghasilkan gerakan semu seolah-olah matahari mengelilingi bumi selama 24 jam. Yang membedakan di antara kalender-kalender tersebut, yaitu pendefinisian dimulainya sebuah hari. Kalender Gregorian, awal hari didefinisikan pada tengah malam (jam 24:00), sedangkan dalam kalender Islam, awal hari dimulai pada saat matahari terbenam di ufuk barat.

Dalam penentuan bulan dalam kalender Islam, menentukan awal bulan murni berdasarkan pada perjalanan bulan dalam berevolusi (mengelilingi) bumi. Namun, untuk menentukan jam dan menitnya waktu prosesi ibadahnya ternyata didasarkan pada bumi yang berotasi pada sumbunya sehingga berefek pada gerakan semu matahari yang seolah-olah mengelilingi bumi. Misalnya saja penentuan awal bulan Ramadhan memang murni berdasarkan perjalanan bulan dengan ditandai adanya hilal yang muncul setelah matahari terbenam pada akhir bulan Sya'ban. Namun detail prosesi ibadah setiap harinya murni ditentukan oleh pergerakan semu matahari mengelilingi bumi. Awal prosesi puasa setiap harinya ditandai dengan awal waktu shalat Subuh dan diakhiri pada awal shalat Maghrib.

Kalender ini mulai dipakai pada tahun $622 \mathrm{M}$ dengan hari pertamanya diambil dari hijrah pada Nabi Muhammad dan para sahabat dari Makkah ke Madinah. Oleh karenanya juga disebut kalender Hijriyah. Hijrah ini merupakan perintah Allah setelah selama 13 tahun resistensi kaumnya di Makkah atas ajaran Nabi.

Adapun hari-hari dalam Islam tetap mengikuti urutan agama sebelumnya (Yahudi dan Nasrani) yang dimulai dengan Minggu dan berakhir dengan Sabtu. Dengan demikian, meskipun Jum'at adalah hari libur bagi umat Islam, Jum'at sendiri tidak menunjukkan hari pertama atau hari terakhir dalam satu minggu menurut Kalender Islam. ${ }^{12}$ Hari-hari tersebut adalah: (1) Yaum al-Ahad (hari pertama)- Ahad/Minggu, (2) Yaum al-Istnain (hari kedua) - Senin, (4) Yaum alTsalâtsa (hari ketiga) - Selasa, (4) Yaum al-Arba'a (hari keempat) - Rabu, (5) Yaum al-Khâmis (hari kelima)Kamis, (6) Yaum al-Jumû'ah (hari berkumpul)Jum'atYaum al-Sabt (hari sabath) - Sabtu.

\section{Dasar Hukum Kalender Islam}

Hal menarik dalam Islam bahwa Islam mengatur cukup jelas meskipun tidak detail tentang tingkah laku manusia bahkan sampai pada perhitungan dan pengorganisasian waktunya. Hal ini dijelaskan dalam kitab

12 Tono, Mengkompromikan Rukyat \& Hisab, h. 68. 
suci al-Qur'an dan hadits Nabi sebagai penjelasnya. Perhitungan kalender Islam, dihitung berdasarkan petunjuk dalam al-Qur'an surat al-Taubah ayat 36-37:

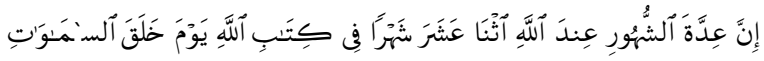

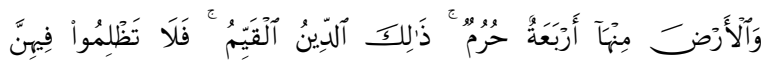

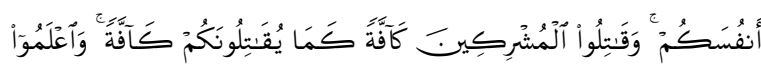

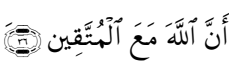

Sesungguhnya bilangan bulan pada sisi Allah adalah dua belas bulan, dalam ketetapan Allah di waktu Dia menciptakan langit dan bumi, di antaranya empat bulan haram. ${ }^{13}$ Itulah (ketetapan) agama yang lurus, maka janganlah kamu menganiaya diri ${ }^{14}$ kamu dalam bulan yang empat itu, dan perangilah kaum musyrikin itu semuanya sebagaimana merekapun memerangi kamu semuanya, dan ketahuilah bahwasanya Allah beserta orang-orang yang bertakwa.

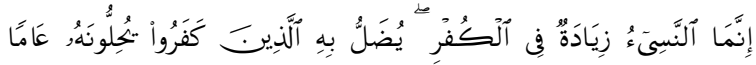

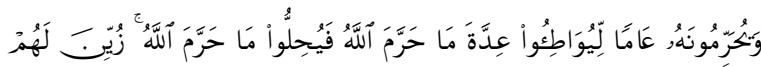

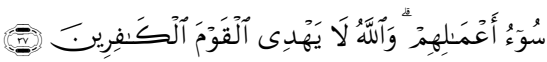

Sesungguhnya mengundur-undurkan bulan Haram itu ${ }^{15}$ adalah menambah kekafiran. disesatkan orang-orang yang kafir dengan mengundur-undurkan itu, mereka menghalalkannya pada suatu tahun dan mengharamkannya pada tahun yang lain, agar mereka dapat mempersesuaikan dengan bilangan yang Allah mengharamkannya, Maka mereka menghalalkan apa yang diharamkan Allah. (syaitan) menjadikan mereka memandang perbuatan mereka yang buruk itu. dan Allah tidak memberi petunjuk kepada orang-orang yang kafir.

Dua ayat di atas, merupakan sebuah indikasi bahwa Allah tidak menghendaki penggunaan kalender dengan interkalasi (sisipan), sebagaimana di gunakan dalam kalender Yahudi, Cina dan Hindu. Sementara kalender Gregorian melakukan interkalasi pada setiap

13 Maksudnya antara lain ialah: bulan Haram (bulan Dzulqa'dah, Zulhijjah, Muharram dan Rajab), tanah Haram (Makkah) dan ihram.

14 Maksudnya janganlah kamu Menganiaya dirimu dengan mengerjakan perbuatan yang dilarang, seperti melanggar kehormatan bulan itu dengan Mengadakan peperangan.

15 Muharram, Rajab, Dzulqa'dah dan Zulhijjah adalah bulan-bulan yang dihormati dan dalam bulan-bulan tersebut tidak boleh diadakan peperangan. tetapi peraturan ini dilanggar oleh mereka dengan Mengadakan peperangan di bulan Muharram, dan menjadikan bulan Safar sebagai bulan yang dihormati untuk pengganti bulan Muharram itu. Sekalipun bulangan bulanbulan yang disucikan yaitu, empat bulan juga. tetapi dengan perbuatan itu, tata tertib di Jazirah Arab menjadi kacau dan lalu lintas perdagangan terganggu. bulan berupa sisipan hari menjadi 30 atau 31 hari, disamping satu hari sisipan pada tanggal 29 Pebruari pada tahun kabisat. Satu-satunya kalender yang tidak ada interkalasinya adalah kalender Islam, karena kalender ini sesuai dengan nash al-Qur'an.

Seperti dijelaskan di atas, bahwa dalam penentuan hari dalam kalender Islam tidak seperti kalender lainnya, kalender Islam menentukan awal hari pada saat matahari terbenam, sedangkan awal sebuah bulan dengan dilihatnya bulan baru (hilal) yang dapat dilihat sesaat setelah matahari terbenam. Pedoman syari'ah yang fundamental dalam menentukan awal bulan puasa misalnya tercantum dalam surat al-Baqarah ayat 185 :

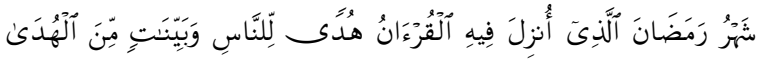

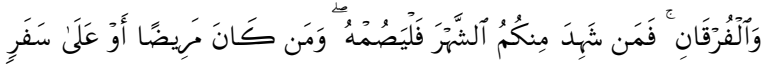

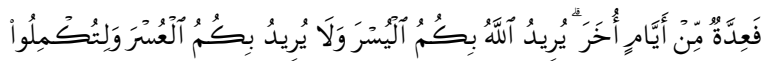

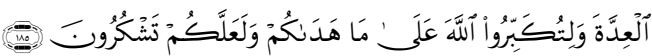

(Beberapa hari yang ditentukan itu ialah) bulan Ramadhan, bulan yang di dalamnya diturunkan (permulaan) al-Quran sebagai petunjuk bagi manusia dan penjelasan-penjelasan mengenai petunjuk itu dan pembeda (antara yang hak dan yang bathil). karena itu, barangsiapa di antara kamu hadir (di negeri tempat tinggalnya) di bulan itu, maka hendaklah ia berpuasa pada bulan itu, dan barangsiapa sakit atau dalam perjalanan (lalu ia berbuka), maka (wajiblah baginya berpuasa), sebanyak hari yang ditinggalkannya itu, pada hari-hari yang lain. Allah menghendaki kemudahan bagimu, dan tidak menghendaki kesukaran bagimu. dan hendaklah kamu mencukupkan bilangannya dan hendaklah kamu mengagungkan Allah atas petunjuk-Nya yang diberikan kepadamu, supaya kamu bersyukur. ${ }^{16}$

Selain nash-nash al-Qur'an sebagai dasar penentuan awal bulan, hadits Nabi juga menjelaskan tentang hal tersebut: ${ }^{17}$

Hadits Riwayat. Muslim

$$
\begin{aligned}
& \text { حدثنا يحي بن يحي قال: قرأت على مالك، عن نافع، عن ابن عمر رضي الله عنهه }
\end{aligned}
$$

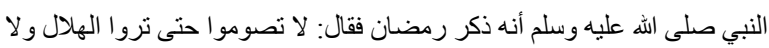

$$
\begin{aligned}
& \text { تفطروا حتى تروه، فإن أغمي عليكم فقدرو اله }
\end{aligned}
$$

"Telah mengabarkan kepada kami Yahya bin Yahya, dia berkata saya bacakan kepada Malik, dari Nafi', dari Ibn Umar r.a. dari Nabi saw. sesungguhnya beliau membicarakan tentang Ramadhan, lalu beliau

\footnotetext{
16 Ibid., h. 66-72

17 Maskufa, Ilmu Falak, (Jakarta: Gaung Persada Press, 2009), h. 152.
} 
bersabda: "Jangan kalian (kamu semua memulai) berpuasa (masuk tanggal 1-Ramadhan) sehingga kamu melihat hilal, dan janganlah kalian mengakhiri puasa (masuk tanggal 1-Syawwal) sehingga kamu melihatnya (hilal lagi). Jika kamu terhalang maka perhitungkanlah."

Hadits Riwayat. Imam Bukhari

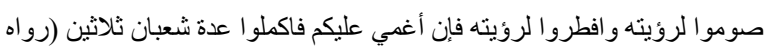

(البخاري) (2) (n)

"Berpuasalah karena kamu melihat hilal dan berbukalah karena kamu melihat hilal. Apabila hilal itu tertutup debu atasmu maka sempurnakanlah bilangan Sya'ban tiga puluh hari"

\section{Mohammad Ilyas Dan Kalender Islam Interna- sional}

\section{Sekilas tentang Mohammad Ilyas}

Mohammad Ilyas adalah seorang fisikawan dan ahli mengenai atmosfer yang banyak menulis tentang astronomi Islam. Beliau adalah salah seorang pengajar di Universitas Sains Malaysia dan sebagai kepala Unit Penyelidikan Ilmu Falak (Astronomy and Atmospheric Research Unit). Beliau aktif melakukan berbagai penelitian dan menulis artikel di jurnal. Salah satu karyanya yang terkenal dan merupakan magnum opusnya adalah A Modern Guide to Astronomical Calculations of Islamic Calender, Times and Qibla, yang terbit pertama kali pada tahun 1984 oleh berita publishing Kuala Lumpur dan dicetak ulang oleh Washington DC pada tahun 1992. Di antara beberapa karyanya adalah New Moon's Visibility and International Islamic Calender for the Asia Pasific Region, 1407-1421 H, Astronomi of Islamic Calender dan karya terbarunya yang diterbitkan dalam bahasa melayu, yaitu Kalender Islam dari Perspektif Astronomi. Melalui karya-karya tersebut, beliau dikenal sebagai salah seorang penggagas kalender Islam internasional.

Selain menjadi pengajar, Ilyas juga aktif melakukan penelitian dan menulis artikel di berbagai jurnal regional maupun internasional. Tulisan-tulisannya memfoskuskan pada persoalan kalender Islam. Sebagai seorang ilmuwan, Ilyas termasuk salah satu ilmuwan yang responsif dan produktif.

Selama 18 tahun (1976-1994) Ilyas menghasilkan 123 artikel dan buku-buku yang berkaitan dengan kalender Islam Internasional, seperti New Moon's Visibility and International Islamic Calender for the Asia Pacific Region, 1407-1421 H diterbitkan oleh Organization of Islamic Conference (OIC) Standing Committee on Scientific and Tachnological Cooperation (COMSTECH) Islamabad, Pakistan dan Regional Islamic Da'wah Council of South East Asia and Pacific (RISEAP) Kuala Lumpur, Malaysia dan Astronomy of Islamic Calender yang diterbitkan oleh A.S. Noordeen Kuala Lumpur. Karya terbarunya diterbitkan dalam bahasa Melayu dengan judul Kalender Islam dari Perspektif Astronomi. Oleh karenanya, Ilyas dikenal sebagai penggagas konsep Kalender Islam Internasional. ${ }^{18}$

\section{Pemikiran dan Gagasan tentang Kalender Islam Internasional}

Sebagaimana disinggung di atas, bahwa Mohammad Ilyas merupakan salah satu pemikir muslim yang gigih berusaha mempersatukan kalender Hijriyah di seluruh dunia. Pada dasarnya gagasannya Mohammad Ilyas ini merupakan pengembangan dari pemikiran yang dirintis oleh pemikir Islam sebelumnya seperti Ibnu Taimiyah, Ahmad Muhammad Syakir, Abu Zahroh dan T.M. Hasbi ash-Shiddieqy. Namun pemikiran tokoh-tokoh tersebut tertuang hanya sebatas teori normatif deduktif. Sementara Ilyas tidak hanya dalam dataran teori namun didukung data empiris yang memanfaatkan sains modern. Untuk mendukung gagasannya, Ilyas melakukan riset selama kurang lebih 20 tahun (2973-1993).

Sebagai seorang ilmuwan muslim, Ilyas merasa mempunyai tanggung jawab terhadap masa depan umat Islam, terutama terpeliharanya persatuan umat yang terjalin dalam ukhuwah islamiyah. Bentuk dari tanggung jawab tersebut, beliau wujudkan dalam ideidenya yang berkaitan dengan penyatuan kalender Islam internasional. Beliau mengungkapkan seorang muslim, dituntut untuk berusaha memecahkan masalah-masalah yang timbul dalam masyarakat Islam. Kalender Islam adalah suatu masalah mendasar di masyarakat Islam. Pada dasarnya pemecahan masalah ini merupakan persoalan ilmiah dan sebagai seorang ilmuwan saya merasa berkewajiban untuk turut mengatasi masalah ini.

Kesadaran Ilyas akan gagasannya tentang Kalender Islam Internasional tidak lepas dari situasi dan kondisi objektif pada saat itu. Di Malaysia misalnya, muncul kelompok tradisionalis, modernis dan reformis. Akibatnya menimbulkan konsep dan konotasi tertentu yang tidak kondusif bagi ukhuwah

\footnotetext{
18 Susiknan Azhari, Hisab dan Rukyat, Wacana untuk Membangun Kebersamaan di Tengah Perbedaan, (Yogyakarta: Pustaka Pelajar, 2007), h. $25-26$
} 
islamiyah. Berdasarkan kenyataan di atas, maka Ilyas berusaha mendamaikan Islam melalui proyek besar Kalenderisasi Islam Internasional. Proyek ini direalisasikan melalui International Islamic Calender Program (IICP) yang bermarkas di Universitas Sains Malaysia, Penang. Hasil-hasil riset ini kemudian disebarkan ke negara-negara Islam yang tergabung dalam Organisasi Konferensi Islam (OKI), kemudian didialogkan melalui pertemuan-pertemuan regional dan internasional, misalnya pada Konferensi Turki tentang Unifikasi Kalender Islam Internasional pada tahun 1978 dan Seminar Penanggalan Islam Internasional pada tanggal 8-10 Juni 1988 di Malaysia.

Sayangnya respon masyarakat Islam pada saat itu terfokus pada masalah klasik hisab rukyat, bahkan sampai sekarang. Semangat gagasan Ilyas kurang diapresiasi secara positif oleh peserta konferensi. Bahkan menurut Abdur Rachim, peserta dari Indonesia, Arab Saudi belum bisa menerima gagasan Ilyas tentang Imkanur Rukyat. ${ }^{19}$

Kalender yang diusulkan oleh Ilyas didasarkan pada dua unsur pokok, sebagai berikut:Pertama, hisab Imkanur Rukyat, yang sekaligus untuk menemukan; dan Kedua, Garis Tanggal Qamariyah Internasional (ILDL)

Hisab Imkanur Rukyat Ilyas menggunakan kriteria yang merupakan kombinasi dua parameter yaitu parameter ketinggian relatif geosentrik (geosentrik relative altitude) dan parameter azimut relatif (relative azimut). Dalam hisab ini hanya ada satu kategori Imkanur Rukyat yaitu hilal yang mungkin terlihat.

Hisab Imkanur Rukyat ini, dilakukan diberbagai tempat (secara global) untuk menemukan titik-titik Imkanur Rukyat. Misalnya hisab dimulai dari titik $0^{\circ}$ guna menemukan titik visibilitas hilal pertama, kemudian dilakukan pada garis lintang berikutnya ke utara dan ke selatan dengan interval $5^{\circ}$ sampai $15^{\circ}$ guna menemukan titik Imkanur Rukyat. Apabila hal tersebut telah dilakukan dan telah ditemukan titiktitik Imkanur Rukyat, maka titik-titik visibilitas tersebut dihubungkan dengan satu garis, sehingga akan ditemukan garis lengkung (parabolik) yang lengkungannya menjorok ke timur. Garis itu akan memisahkan dua kawasan bumi yaitu kawasan sebelah barat dan sebelah timur. Kawasan sebelah barat adalah kawasan yang mungkin melihat hilal dan kawasan timur sebagai kawasan yang tidak mugkin bisa melihat hilal (dengan catatan bahwa garis tersebut tidak bersifat eksak dan muncul berpindah-pindah

19 Susiknan, Hisab Dan Rukyat, h.26-28. setiap bulan).

Apabila garis ini membelah suatu negara menjadi dua, maka dapat ditarik ke arah timur sesuai dengan batas negara bersangkutan. Garis inilah yang disebut dengan Garis Tanggal Qamariyah Internasional (GTKI). Atas dasar GTKI ini, Ilyas merumuskan Kalender Islam Internasional, namun bersifat zonal dan membagi bumi menjadi tiga zona tanggal yaitu zona Asia-Pasifik, zona Eropa, Asia Barat serta Afrika dan zona Amerika. ${ }^{20}$

Garis Tanggal Qamariyah Internasional (GTKI) atau lebih popular dengan sebutan ILDL, merupakan gagasan orisinil dari Ilyas. Ide ini kemudian di respons oleh berbagai kalangan ilmuwan dengan berbagai komentar. Dengan gagasannya ini bukan berarti Ilyas akan menegasikan realitas empiris, melainkan berencana menunjukkan inti masalah jika diinginkan kajian yang ilmiah atas Kalender Islam Internasional. Bagi Ilyas, kajian ilmiah atas Kalender Islam Internasional tidak dapat ditawar-tawar karena kalender merupakan produk sejarah, maksudnya peran logika atau ijtihad lebih dominan dalam menentukan datadata yang diperoleh dari fenomena alam. Jadi, menurut Ilyas berpendapat dan berdialog tentang Kalender Islam Internasional, khususnya tentang persoalan Garis Tanggal Qamariyah Internasional antar bangsa akan berjalan dengan baik jika masing-masing pihak dibekali dengan pendidikan dan pemahaman yang holistik-komprehensip. Hal ini sejalan dengan pemikiran Moedji Raharto yang mengusulkan perlunya pemahaman kalender Islam bagi umat Islam sendiri, agar kalender Islam lebih memasyarakat.

Berdasarkan pengamatan Ilyas, kebanyakan Negara Islam masih sangat lemah dalam sains dan teknologi. Problem dalam kalender Islam Internasional merupakan cermin akan hal ini, kelemahan tersebut menyebabkan dalam perhitungan kalender dengan metode yang berbeda-beda dan belum dapat dipersatukan.

Namun dengan gagasannya, Ilyas tidak menegasikan adanya perkembangan paradigma di kalangan tokoh agama dalam beberapa tahun terakhir ketika mendisukusikan persoalan Garis Tanggal Qamariyah Internasional antar bangsa. Menurut Susiknan, sikap keberatan para tokoh agama akan Garis Tanggal Qamariyah Internasional antar bangsa, dikarenakan tidak lepas dari kultur berpikir yang selama ini dipegangi, yaitu antara model Syafi'i dan Abu Hanifah. Imam

20 Syamsul Anwar, Perkembangan Upaya Penyatuan Kalender Internasional, (Seminar Nasional: Penentuan Awal Bulan Qamariyah di Indonesia, Yogayakarta 27-30 Nopember 2008), h. 5 
Syafi'i berpandangan bahwa hasil observasi hanya berlaku lokal, sedangkan Abu Hanifah berpendapat hasil rukyat berlaku global.

Pada dasarnya Ilyas ingin keluar dari perdebatan tersebut dengan melakukan kajian secara ilmiah yang memadukan antara khazanah Islam klasik dan modern. Dalam kerangka inilah Ilyas menawarkan Garis Tanggal Qamariyah Internasional antar bangsa, yang diklaim sebagai proyek masa depan umat dengan merubah local oriented menjadi global oriented. Dengan menggunakan Garis Tanggal Qamariyah Internasional antar bangsa akan mudah ditentukan umur bulan (29 hari atau 30 hari) di suatu tempat di permukaan bumi. Dengan Garis Tanggal Qamariyah Internasional antar bangsa juga diharapkan semangat persatuan umat Islam di seluruh dunia. Menurut Ilyas, Garis Tanggal Qamariyah Internasional antar bangsa digunakan karena paling mudah menghitungnya dan bisa dipakai sebagai pemandu awal oleh pengguna rukyat terpandu hisab sebelum menghitung data rukyat lokal. Garis Tanggal Qamariyah Internasional antar bangsa membagi bumi menjadi dua bagian pada saat Maghrib bulan masih di atas ufuk atau sudah terbenam. Pembagian inilah yang menjadikan problem klasik tetap ada, yaitu persoalan matla'.$^{21}$

Moh. Ilyas telah mengkaji kriteria tampaknya hilal yang digunakan oleh astronom-astronom klasik maupun modern, dan Ilyas telah memperbaikinya dengan cara menggabungkan pendekatan-pendekatan baik secara teori dan terapan. Sebagaimana keilmuan yang lain, dalam penentuan kriteria ini juga membutuhkan proses yang berkembang secara berangsur-angsur, dan diperbaiki dari masa ke masa. Komponen-komponen kalender Islam yang seragam dan menyeluruh adalah sebagai berikut: Suatu sistem yang rapi mengenai perkiraan kedudukan matahari dan bulan, penetapan kriteria astronomi yang diperlukan untuk tampaknya hilal dan penentuan tidak mungkinnya hilal untuk dirukyat, penggunaan secara menyeluruh Garis Tanggal Qamariyah, kemungkinan untuk merayakan hari-hari keagamaan secara bersamaan..$^{22}$

Menurut hemat penulis, gagasan yang diajukan oleh Ilyas merupakan gagasan yang brilliant, dengan usaha untuk menyatukan umat Islam yang selama ini selalu berbeda dalam menentukan waktu-waktu ibadah mereka. Namun, sebagaimana yang dibahas pada

\footnotetext{
21 Susiknan Azhari, Hisab dan Rukyat, h. 29-31.

22 Mohammad Ilyas dan M. Khalid-Taib, Pengantarabangsaan Kalender Islam Perspektif Asia Pasifik, (Seminar dan Bengkel Serantau tentang Kalender Islam Antarabangsa, University Sains Malaysia 8-10 Juni 1988), h. 20-21.
}

Seminar Internasional yang diadakan oleh Majlis Tarjih Muhammadiyah di Yogyakarta bahwa GTKI yang diusulkan oleh Ilyas tersebut tidak tetap dan selalu berpindah-pindah garis tanggal setiap bulannya sehingga tidak memberi kepastian dan kemudahan. Selain itu, GTKI Ilyas tidak dapat menyatukan tanggal hijriyah, padahal tujuan utama adalah penyatuan tanggal hijriyah di seluruh dunia. Hal ini tidak mungkin karena setiap upaya perumusan kalender dengan membuat garis tanggal baru Qamariyah, maka secara otomatis akan berakhir dengan terjadi dua tanggal untuk satu hari yang sama atau dua hari untuk satu tanggal. Hal ini dikarenakan telah adanya Garis Tanggal Internasional yang telah disepakati secara internasional oleh dunia. Misalnya saja, garis tanggal Qamariyah jatuh di (melewati) kota Makkah pada suatu bulan, maka secara otomatis kawasan antara Makkah dan garis BT $180^{\circ}$ akan terlambat satu hari memasuki bulan baru, sehingga untuk satu tanggal Qamariyah ada dua hari yang berbeda. Hal mendasar yang menjadi pertanyaan, apakah mungkin Kalender Islam Internasional dapat dibuat tanpa membuat garis tanggal baru agar tidak terjebak dengan adanya satu tanggal untuk dua hari yang berbeda. ${ }^{23}$

Selain itu, menurut penulis bahwa ide mengenai Kalender Islam Internasional yang diajukan oleh Moh. Ilyas tersebut, tidak dapat diterima semua kalangan dengan lapang dada. Banyak faktor yang melatarbelakangi kelompok-kelompok dengan metode masing-masing dalam penentuan awal bulan Qamariyah. Misalnya saja, penulis mencoba melihat fenomena yang ada di Indonesia, dalam hal ini banyaknya kelompok yang ada di Indonesia dengan berbagai metode yang berbeda-beda dalam penentuan awal bulan Qamariyah, sangat sulit didekati oleh pemerintah yang notabenenya memiliki otoritas untuk menyatukan prinsip dalam penentuan waktu-waktu ibadah umat Islam. Bahkan untuk kelompok yang masih kolot, berpindah dari metode yang terbilang klasik dan salah saja dan menerima keilmuan yang lebih akurat sangat sulit karena ada keyakinan yang kuat akan kebenaran metode yang dipegangi selama ini. Hal ini masih di antara umat Islam di Negara Indonesia yang sudah sangat majemuk, belum lagi di negara-negara lainnya.

\section{Kesimpulan}

Gagasan Moh. Ilyas tentang Kalender Islam Internasional yang bertujuan untuk kesatuan umat

23 Syamsul Anwar, Perkembangan Upaya Penyatuan Kalender Internasional, h. 8 . 
Islam, bukan berarti berjalan mulus tanpa hambatan. Problematika penentuan awal bulan Qamariyah tidak hanya bertumpu pada keilmuan yang bersifat eksak seperti astronomi, namun merupakan juga permasalahan fiqh, permasalahan politis, serta permasalahan sosiologis. Jadi tidak begitu saja suatu kelompok menerima ide baru, dikarenakan sudah mengakarnya dengan metode yang selama ini

\section{Daftar Pustaka}

Ahmad, Noor. tt. Risâlah Sayms al-Hilâl. Kudus: Madrasah Tasywiqât-Tullâb Salâfiyah.

Al-Khatib, Ahmad. tt. A New Dictionary of Scientific \& Technical Terms. Libanon: Maktabah Libanon.

Anwar, Syamsul. 2008. Perkembangan Upaya Penyatuan Kalender Internasional. Seminar Nasional: Penentuan Awal Bulan Qamariyah di Indonesia, Yogayakarta 27-30 Nopember 2008.

Azhari, Susiknan. 2007. Hisab dan Rukya, Wacana untuk Membangun Kebersamaan di Tengah Perbedaan. Yogyakarta: Pustaka Pelajar.

Ba'albaki, Munir. 1974. al-Mawrid A Modern English-Arabic Dictionary. Beirut: Dâr al-'Ilm li al-Malâyin.

Departemen Pendidikan dan Kebudayaan. 1989. Kamus Besar Bahasa Indonesia. Jakarta: Balai Pustaka.

Departemen Pendidikan dan Kebudayaan. 1995. Kamus Besar Bahasa Indonesia. Lihat juga John L. Esposito. The Oxford Encyclopaedia of Modern Islamic World. New York: Oxford University Press.

Ilyas, Mohammad dan Taib, M.Khalid. 1988. Pengantarabangsaan Kalender Islam Perspektif Asia Pasifik, Seminar dan Bengkel Serantau tentang Kalender Islam Antarabangsa: University Sains Malaysia 8-10 Juni 1988. diaplikasikan. Selain itu, ide Kalender Islam Internasional dengan penentuan Garis Tanggal Qamariyah masih memunculkan berbagai pertanyaan yang perlu dijawab. Metode Imkanur Rukyat yang ditawarkan masih perlu diuji dan observasi lebih lanjut untuk menghasilkan data yang akurat yang akhirnya dapat diterima oleh semua kalangan.

Khafid. 2009. Kalender Islam Internasional: Analisis terhadap Perbedaan Sistem, Disertasi.

Khair bin Mohamad Taib, Mohamad. Tt. Takwim Istilah (Hijhrah-Masehi) 1401-1500 H./19802077 M, Kuala Lumpur: Jabatan Perdana Menteri [Bahagian Ugama] Pusat Islam.

Khazin, Muhyidin. 2008. Ilmu Falak dalam Teori dan Praktik. Yogyakarta: Buana Pustaka.

Maskufa. 2009. Ilmu Falak. Jakarta: Gaung Persada Press.

Montenbruck, Oliver dan Pfleger, Thomas. 1994. Astronomy on The Personal Computer. Berlin: Spinger-Verlag.

Munawwir, Ahmad Warson. Tt. Kamus al-Munawwir Arab-Indonesia Terlengkap. Surabaya: Pustaka Progresif.

Murtadho, Moh. 2008. Ilmu Falak Praktis. Malang: UIN Malang Press.

Panji Masyarakat, No. 582, 7-16 Dzulhijjah 1408/2130 Juli 1988.

Panji Masyarakat, No. 718. Tahun XXXIV, 28 Syawal - 7 Dzulqa'dah 1412 H./1-10 Mei 1992 M.

Saksono, Tono. 2007. Mengkompromikan Rukyat \& Hisab. Jakarta: P.T. Amythas Publicita.

Steingass, F. 1978. Arabic-English Dictionary. New Delhi: Cosmo Publications.

Wehr, Hans.1994. Dictionary of Modern Written Arabic. Germany: Otto Harrassonitz. 